\title{
Diseases are invisible
}

\section{S Fredriksen}

J Med Ethics: Medical Humanities 2002;28:71-73

The success of modern medicine is closely related to its ability to transcend the human senses. Technological advances such as stethoscopes, microscopes, and $x$ rays overstep the boundaries of human perception. They enable us to see what is invisible to the unaided senses. These technologies have brought about fundamental changes to medicine-for the most part for the better. But they have also caught us in a tragic trap. They have left us in an odd position where we can no longer trust our senses concerning the health status of our body. Sense transcending technologies have made us aware that we can have a serious disease without experiencing any symptoms at all. In order to benefit from these technologies, we have to live with inescapable side effects.

M odern medicine is about two hundred years old. It was born in the beginning of the nineteenth century, when sense transcending technologies for the first time made an impact on medical practice. The invention of the stethoscope in 1816 probably represents the most distinctive and illustrative event in the transformation process. ${ }^{1}$ When it was taken into practice, doctors for the first time started to use technology in order to investigate the interior of the bodies of living patients. A totally new way of looking at things emerged.

This event represents more than the introduction of a new piece of equipment. The first stethoscope was a piece of paper rolled into a tube and held to the chest. This could have been done at any time in human history. Many murmurs and sounds of the heart and the lungs can be heard by placing the ear on the chest wall. Some can even be heard at the bedside. The invention and introduction of the stethoscope was accompanied by a change of perspective on the nature of diseases.

\section{PREMODERN MEDICINE}

Before the nineteenth century, in premodern medicine, nature was our ally. Nature and human comprehension were considered two of a kind. Galen and his theory of the four body fluids can be used as an illustration of this. It remained part of the stock in trade of medicine for an incredible fifteen hundred years. But Galenic medicine is too unfamiliar and archaic to serve as a contrast to modern medicine in this article. Instead, I will use an abbreviated version of eighteenth century "bedside medicine" as an example. The main virtue of bedside medicine was observation-not unlike the credo of today. But the theoretical, or epistemological, foundation underlying this observation was radically different from ours. Practitioners of "bedside medicine" rested content in the conviction that there was a perfect association between appearance and disease. The two were in some sense considered identical. $^{2}$

The appearance-the symptoms and the signs-were considered sufficient to unravel and differentiate diseases completely; be it aetiologically, epidemiologically, or therapeutically. Clinical medicine thus became a kind of solving of jigsaw puzzles, where the physicians believed in a pregiven guarantee. They believed that all the pieces-all relevant information-lay on the table facing upwards. No piece lay on the floor or was eaten by a two year old. The challenge was to make the full picture emerge by combining the pieces - the signs and the symptoms-correctly. This work required skill and experience, but there was no need for technology. Diseases were perceptible to the unaided senses. If the physician failed at his task, if the diagnosis or prognosis turned out to be wrong, it was ascribed to an error of judgment. The physician had failed because he had misinterpreted the symptoms, not because relevant information had been unavailable.

This worldview rests on more than rationalism: it depends on more than a trust in reason. Not only did bedside physicians believe that external nature and human thought worked the same way and by the same principles, they also believed that this structure could be displayed through the use of unaided senses. All the secrets of nature would be revealed if they were given proper attention. Humans-our perceptive abilities and our reason combined-were considered completely compatible with nature. The appearance of a disease brought forth its essence, its characterising properties. Hence, if two patients suffered from the same symptoms, then, by virtue of that fact, they suffered from the same disease. One did not probe beneath the surface and did not differentiate between shortness of breath caused by diseases of the lungs, and shortness of breath caused by diseases of the heart.

Practitioners of bedside medicine, and other branches of premodern medicine, believed in a deep harmony in the universe, they believed that nature was made to fit us. They believed that God had sufficiently equipped us to learn everything that we were meant to know.

\section{DESCARTES AND GALILEO'S TELESCOPE}

The attitude in modern medicine is different and distrustful. We do not consider nature our ally. We do not expect her to reveal herself completely from simple observation and deep thinking. We, as one might say with the wisdom of hindsight, have realised that nature contains more than 
meets the eye. We expect a lot of vital information to be invisible to the unaided senses, and hope that some of this information can be revealed with the use of sense transcending technology. We live in the aftermath of Descartes and Galileo; two of the main architects of the modern worldview.

René Descartes (1605-1651) is commonly considered the first modern philosopher. One strain of his reasoning is particularly relevant for this article. Descartes was stunned by the discoveries Galileo Galilei (1564-1642) made with his telescope. ${ }^{3}$ (Probably in much the same way as contemporary physicians were stunned by the discoveries Rene Laennec made with his first stethoscope.) What upset Descartes about Galileo's new cosmology was not that it diminished the status of the earth by removing her from the centre of the universe. He was upset by the fact that perfectly sensible beliefs were proved wrong. The telescope exposed-contrary to all sense experience and all reason-that the earth is moving! This implied a virtual "rape" of the senses, as Galileo put it himself. ${ }^{4}$ Descartes recognised the deep alienation inherent in this discovery. It seemed that we were not completely at home in the universe; that we are inadequately equipped to perceive and to comprehend nature as it really is; that important information is hidden from us.

Descartes faced the problem head on: if comprehension and external nature are completely different things and follow different laws, how can we know anything at all about nature. ${ }^{5}$ How can different things communicate with each other? Descartes (wisely) refused to give in, and I agree with him. It is folly to doubt the existence of an external world looking quite similar to the one we perceive. Complete doubt is a position impossible to hold for more than seconds at a time even under ideal conditions. Then you do something that undermines your scepticism, such as taking a breath.

But Descartes searched for a more secure foundation for knowledge than our daily, serious, and successful acquaintance with nature. He put his trust in God and in Corpus Pineale. He was convinced that God had made us and the world to complement each other. Provided we cautiously followed the right methods, he believed that an almighty and good God would not let us be deceived. He even identified an anatomical structure in the middle of the brain, Corpus Pineale, as the link God had installed between matter and mind; that is, the switch box where external stimulus were transformed into internal thought images.

Today this looks like an invented, quick fix sort of solution. Vital parts of Descartes's construction have broken down. We do not believe in any God-given guarantee. But the division between mind and matter-between comprehension and external nature-has remained. Few of us sincerely doubt the existence of pulmonary oedema, but most of us doubt that we can get any absolute knowledge about this condition. Instead we believe that the scope of possible knowledge is limitless, and we are painfully aware that surprises may lurk around every corner. We believe in progress, but the harmony is gone

\section{MODERN MEDICINE AND THE STETHOSCOPE}

In medicine, as I have already argued, the premodern harmony remained for one and a half centuries after the death of Descartes. Bedside medicine of the eighteenth century had a harmonious core; everything was visible for the ones who were able to interpret the signs and symptoms correctly. Profound changes take time. For lack of a better phrasing, I therefore suggest that the modern worldview had arrived when, in the last decade of the eighteenth century, the pathologist Xavier Bichat (1770-1801), “opened up a few corpses", as Foucault laconically remarks. ${ }^{6}$ Contrary to common belief, autopsies had been carried out for centuries before Bichat reached for the knife, but no one had looked at the body the same way as he did. Porter quotes Bichat thus:
You may take notes for twenty years from morning to night at the bedside of the sick, and all will be to you only a confusion of symptoms ... . a train of incoherent phenomena. (But start cutting bodies open and, hey presto), this obscurity will soon disappear.

Bichat regarded autopsy findings as being more important than the clinical appearance of the disease. The former was the cause of the latter-not the opposite, as practitioners of bedside medicine tended to believe. Bichat paid attention to the signs and symptoms, but was prepared for a real surprise and a total revision of his views when he opened a corpse. Earlier pathologists made autopsies more to confirm what they already knew.

Rene Laennec was in the same way prepared for a surprise when, in 1816, he put his newly invented stethoscope to the chest of living patients. He was prepared to change his judgment and his diagnosis in accordance with the findings he made. He was prepared to neglect what his unaided senses told him, and trust what he heard through the stethoscope, because he believed that the stethoscope, in some cases, gave a more accurate description of reality. Comparisons between auscultation findings and later autopsies convinced him of that. The alienation inherent in this change of view probably never occurred to him.

\section{TRIUMPH AND DESPAIR}

So far I have focused on the early history of modern medicine. There are two reasons for this. For one thing, the stethoscope is not obsolete. It is still a central part of medical practice. Secondly, the current state of affairs is too familiar. To expose the significance and the alienating side effects of sense transcending technology, that technology has to be compared with something different, with an alternative. And an historical account manages just that. It brings to light how things once were-and still could have been-different.

But things are not different. Present day medicine is saturated-not to say defined-by the stethoscope and its technological descendants ${ }^{89}$ : cardiotocography (CTG), magnetic resonance imaging (MRI), computed tomography (CT), ultrasound .... There is no point in trying to mention them all. Medical technology is so ubiquitous, its importance so fundamental, and its side effects so obvious, that a veritable intellectual industry has grown up to criticise it. ${ }^{11}{ }^{11}$ And to some extent, the criticisms are warranted. During the last fifty years, the unquestionable growth of medical knowledge has been accompanied by a simultaneous growth of despair and dissatisfaction. ${ }^{12}$ The story of modern medicine has turned out to be paradoxical: triumph and despair seem to be tragically related. They originate from the same cause-the transcendence of our senses and corresponding alienation of our body.

The success of medical technology has led to an unavoidable distrust of our own senses. Our everyday knowledge is devalued. We know more about diseases today than ever before, but lack confidence in this knowledge. We do not feel sure whether we will perceive any symptoms before it is too late. In despair, we seek medical expertise and technology to interpret and alleviate our worries. Uncertainty prevails because problems often narrow down to a sense transcendent question: is there a test that ought to be taken, is there a question that ought to be asked. Medical success is paid for by a lack of unity and control.

\section{A PRIVILEGED ACCESS TO REALITY}

Imagine that you have stumbled and sprained your ankle. It is swollen and painful. There is no way you can walk on it. You even heard a little crack. You conclude the ankle is broken, and your spouse agrees with you. She drives you to the hospital. The treatment alternatives are plaster or operation. If the 
ankle is broken at the distal tip of the fibula, plaster is sufficient. If it is broken two centimetres further up, an operation is mandatory, and may be the difference between fifty years with or without walking. A misjudgment may have detrimental consequences. The crux is that no one, not even the most experienced orthopaedic surgeon, is able to make this judgment without taking an $x$ ray. The problem is one of technology, not of competence. The $x$ ray gives a privileged access to an otherwise invisible part of reality. The fracture line at the distal end of the fibular bone cannot be visualised using unaided senses. If he had stumbled himself, the orthopaedic surgeon would have to take an $x$ ray of his own ankle to be able to evaluate his situation adequately.

$x$ Rays and other forms of sense transcending technology give us no less than a privileged access to reality-to external nature. An access we cannot gain using natural resources only. Bedside physicians were unable to surpass the results of ordinary home care because they had only rediscovered what ordinary people had always done. Women have been sitting at the bedside watching over their sick from the beginning of time. In order to make a difference, something new had to come up. Luckily it did.

Technology has given anyone able to utilise it a comparative advantage over those who rely only on their bare senses. ${ }^{13}$ Today, sense transcending technologies are prerequisites for medicine's ability to change things to the better. They are perhaps medicine's most distinctive contributions to humankind. It has turned out that "the story behind" - that is, bacteria, cells, electric currents, and blood constituents, are more constant and reproducible than surface appearances. They are more suitable for scientific research and accumulation of knowledge. And I claim that not only solid tools like stethoscopes and microscopes, but also trials, experiments, and statistics, are technologies that help us to throw light on objects and connections that are invisible to the unaided senses. Today, these technologies dominate modern medicine-for better and for worse. Some might argue that we would be better off without most of these technologies. I disagree. Technology has made it possible to prevent, cure, and alleviate diseases on a huge scale: at the same time as it has caught us in a tragic trap of despair. Tragic because benefits and losses are to a large part inseparable. They spring from the same cause. If we want to benefit from the technologies-and we do-we are caught in a conflict we just have to accept and learn to live with.

Any way out of this situation, that is, any detrimental critique of the reign of technology in contemporary medicine, has to come from some place outside technology's own territory. An alternative point of reference has to be found, because all arguments along the line of " $x$ rays are used to excess", "screening for HIV is useless" or "we were wrong when we advised parents to place their children on their stomachs", implicitly allow technology a significant and legitimate site inside medicine. If $x$ rays are used to excess, there has to be some standard for their proper use. If screening for HIV is useless, there has to be something that is useful. If we were wrong, it has to be in comparison with something that is right. The irony is that the standards used for comparison, this "something", often turns out to be based on sense transcendent facts.
An alternative stance would have to be a position where we are left with nothing else than our natural ability to act, observe, and reason. It would be a world where penicillin and $x$ rays did not exist. I think most of us would such a world less tempting than the one we have.

\section{CONCLUSION}

We have to learn to live with the possibilities opened up by the technology-without being completely seduced by them. Medicine is, at rock bottom, a normative and not a technoscientific enterprise. Values such as care, compassion, and solidarity give medicine direction and legitimation, not sense transcendence, precision or truth as such. Technology is a valuable tool in the pursuit of normative ends, but it is not an end in itself. An $x$ ray picture cannot reveal that this particular patient ought to be operated on; a randomised controlled cannot reveal that this patient group ought to receive treatment. Medical decision making will always include normative judgments, explicitly or implicitly. No matter how reliable the facts of the situation are, in a medical evaluation there will always be a decisive a decision point where we have to stand responsible for ourselves. Technology can inform and assist our deliberations, but it can never be a substitute for human judgment.

\section{ACKNOWLEDGEMENT}

I would like to thank my brother, Gaute Fredriksen, for his advice and invaluable discussions both before, and during, the writing of this article.

\section{FUNDING}

The project is financed by the Norwegian Research Council

\section{REFERENCES AND NOTES}

1 The importance of Laennec's invention of the stethoscope is supported by different authors. See: Porter R. The greatest benefit to mankind. London: Fontana Press, 1999; Foucault M. The birth of the clinic. Bristol: J W Arrowsmith Ltd, 1991; Reiser SJ. Medicine and the reign of technology. Cambridge: Cambridge University Press. 1978.

2 See reference 1: all the authors referred to, discuss bedside medicine. 3 Arendt H. The human condition. Chicago \& London: The University of Chicago Press, 1989: 274-5.

4 See reference 3: 274

5 Descartes R. Discourse on method and the meditations. London: Penguin, 1968.

6 Foucault M. The birth of the clinic. Bristol: J W Arrowsmith Ltd, 1991 124-48. Open up a few corpses is the title of the chapter in which Foucault writes most extensively about Bichat.

7 Porter R. The greatest benefit to mankind. London: Fontana Press, 1999: 307

8 This is one of the main theses in Reiser SJ. Medicine and the reign of technology. Cambridge: Cambridge University Press, 1978.

9 Hofmann B. The technological invention of disease. Journal of Medical Ethics: Medical Humanities 2001;27:10-19

10 Illich I. Medical nemesis: the expropriation of health. London: Calder and Boyars, 1975.

11 Skrabanek $\mathbf{P}$. The death of human medicine and the rise of coercive healthism. London: Social Affairs Unit, 1994.

12 Le Fanu J. The rise and fall of modern medicine. London: Little Brown, 1999.

13 The advantage is of course not given only to members of the medical profession. It is given to anyone sufficiently trained in a technology. Many diabetics measure their blood glucose at home and adjust their insulin dosage singlehandedly. 